ARTICLE

\title{
Enterohemorrhagic Escherichia coli senses low biotin status in the large intestine for colonization and infection
}

Bin Yang ${ }^{1,2, \star}$, Lu Feng ${ }^{1,2,3,4,5, \star}$, Fang Wang ${ }^{1,2}$ \& Lei Wang ${ }^{1,2,3,4}$

Enterohemorrhagic Escherichia coli (EHEC) is an important foodborne pathogen that infects humans by colonizing the large intestine. Here we identify a virulence-regulating pathway in which the biotin protein ligase BirA signals to the global regulator Fur, which in turn activates LEE (locus of enterocyte effacement) genes to promote EHEC adherence in the low-biotin large intestine. LEE genes are repressed in the high-biotin small intestine, thus preventing adherence and ensuring selective colonization of the large intestine. The presence of this pathway in all nine EHEC serotypes tested indicates that it is an important evolutionary strategy for EHEC. The pathway is incomplete in closely related small-intestinal enteropathogenic E. coli due to the lack of the Fur response to BirA. Mice fed with a biotin-rich diet show significantly reduced EHEC adherence, indicating that biotin might be useful to prevent EHEC infection in humans.

\footnotetext{
${ }^{1}$ TEDA Institute of Biological Sciences and Biotechnology, Nankai University, TEDA, Tianjin 300457, P.R. China. ${ }^{2}$ Key Laboratory of Molecular Microbiology and Technology, Ministry of Education, Tianjin 300071, P.R. China. ${ }^{3}$ Tianjin Key Laboratory of Microbial Functional Genomics, Tianjin 300457, P.R. China. ${ }^{4}$ State Key Laboratory of Medicinal Chemical Biology, Nankai University, Tianjin 300071, P.R. China. ${ }^{5}$ SynBio Research Platform, Collaborative Innovation Center of Chemical Science and Engineering (Tianjin), Tianjin 300072, P.R. China. ${ }^{\star}$ These authors contributed equally to this work. Correspondence and requests for materials should be addressed to L.W. (email: wanglei@nankai.edu.cn).
} 
E nteropathogenic Escherichia coli (EPEC) and enterohemorrhagic E. coli (EHEC) are important human gastrointestinal pathogens. EPEC causes watery diarrhoea, mainly in children in developing countries ${ }^{1}$. EHEC induces much severer symptoms, producing diarrhoea complicated by haemorrhagic colitis and, sometimes, haemolytic uremic syndrome, which is fatal in $3-75 \%$ of cases ${ }^{2}$. Among the survivors, $30 \%$ show chronic renal failure, hypertension and neurological damage ${ }^{2}$. The two pathotypes differ in two major virulence features: the ability of EHEC and inability of EPEC to produce Shiga toxins; and the colonization of the large intestine by EHEC versus the small intestine by EPEC ${ }^{3}$. Although the molecular basis of Shiga toxins and their implications for pathogenicity have been extensively investigated $^{4}$, the mechanisms behind the site-specific colonization of these two closely related pathotypes are still not well known.

The establishment of successful colonization, characterized by the formation of attaching and effacing $(\mathrm{A} / \mathrm{E})$ lesions, is critical for EHEC and EPEC to cause infection because both bacteria are noninvasive pathogens ${ }^{3}$. The ability to form $\mathrm{A} / \mathrm{E}$ lesions is conferred by the locus of enterocyte effacement (LEE), which consists of five polycistronic operons (LEE1 to LEE5) that are conserved in all A/E-forming pathogens $s^{3,5}$. LEE1 to LEE3 encode a type III secretion system that exports effector molecules; LEE5 encodes the outer membrane adhesin intimin and the translocated intimin receptor (Tir), which are necessary for intimate attachment to the host epithelium; and LEE4 encodes additional type III secretion system structural components, translocator and effector proteins ${ }^{3,5}$. Distinct intimin types have been identified ${ }^{6}$. Intimin $\gamma$-expressing EHEC adhered to distal ileal Peyer's patches, whereas intimin $\alpha$-expressing EPEC adhered to both Peyer's patches and other small intestinal explants based on in vitro human intestinal organ culture adhesion assays $s^{7-10}$. Replacement of intimin $\gamma$ with intimin $\alpha$ in EHEC O157:H7 produces an intimin $\alpha$-like tropism ${ }^{11}$. Site-directed mutagenesis of the receptor-binding site of intimin can also influence bacterial tissue tropism ${ }^{12}$. However, these results cannot fully explain the pathotype-specific tissue tropism between EHEC and EPEC. The initial adherence to host cells may also be promoted by other adhesins, but none of these adhesins were found to be related to the site-specific colonization of EHEC and EPEC ${ }^{13}$.

The expression of LEE genes is regulated by a range of global and specific regulators and is influenced by different environmental stimuli ${ }^{14}$. The human small and large intestines represent two different environments. Several environmental factors present in the human gastrointestinal tract have been found to affect the expression of LEE genes or adherence of EHEC and EPEC by in vitro assays ${ }^{14-18}$. For example, low-pH stress enhanced the adhesion of EHEC to epithelial cells ${ }^{16}$. Adherence to host cells and/or secretion of LEE-encoded virulence factors by EPEC is enhanced by low-pH stress and bile-salt stress ${ }^{17}$ and repressed by ammonium ${ }^{18}$. However, bile-salt treatment had no effect on LEE gene expression in EHEC ${ }^{19}$. Thus, whether these factors are linked to the site-specific colonization of EHEC and EPEC needs to be examined further.

Biotin functions as an essential cofactor for carboxylases and decarboxylases in all organisms. This cofactor can either be synthesized de novo or taken up by microorganisms ${ }^{20}$. In contrast, humans can only obtain biotin from external sources mainly through small intestinal absorption; therefore, higher biotin levels are expected in the small intestine compared with the large intestin $\mathrm{e}^{20,21}$. In $E$. coli, biotin synthesis is tightly controlled in response to biotin supply/demand via the biotin protein ligase BirA, which acts as both the enzyme that funnels biotin into the metabolism and a negative transcriptional regulator of the biotin synthetic operon (bio operon), containing bioA and
bioBFCD $D^{20,22}$. When biotin levels exceed bacterial physiological needs, BirA in complex with biotin binds directly to the 40-bp biotin operator $($ bioO $)$ to repress the transcription of the bio operon $^{23}$. BirA homologues (known as holocarboxylase synthetase) are also present in humans and play regulatory roles in biotin metabolism and transport ${ }^{20,22}$. The $\mathrm{N}$-terminal domain of BirA forms a winged helix-turn-helix motif that is common to many global regulatory proteins ${ }^{24}$. However, no involvement of this biotin-dependent regulator in non-biotinrelated processes has been reported.

EHEC O157:H7 (O157), the most notorious EHEC strain due to its high mortality rate, is thought to have evolved from the less virulent EPEC O55:H7 (O55) ${ }^{25}$. The close relationship between this pair of bacteria makes them suitable for use in comparative studies of the differences in EHEC and EPEC virulence. Genomic comparisons have revealed that genetic determinants acquired during the evolutionary process contribute to the higher virulence of O157:H7, especially Shiga toxin-converting phages and a large virulence plasmid $(\mathrm{pO} 157)^{26}$. However, these analyses provided no hints concerning the molecular basis of the different colonization sites of the bacteria. The expression of LEE genes, which are present in identical copies in the two strains, in response to different conditions in the small and large intestines have not been compared.

In this study, we investigate possible mechanisms underlying the different adherence abilities of EHEC and EPEC. We compare the gene expression profiles of EHEC O157 and EPEC O55 after $3 \mathrm{~h}$ of incubation with HeLa cells using the RNA-Seq technique. In silico analysis through comparative bioinformatics, and in situ functional characterization through quantitative reverse transcription-PCR (qRT-PCR) and mutation assays, reveal the presence of a BirA-mediated biotin signalling regulatory pathway that acts via Fur to control LEE gene expression and bacterial adherence in O157 but not O55. LEE gene expression is positively regulated by Fur in both $\mathrm{O} 157$ and O55. Chromatin immunoprecipitation (ChIP) sequencing (ChIP-Seq) analysis is used to screen possible BirA-binding sites, and ChIP-quantitative PCR (qPCR) and electrophoretic mobility shift (EMSA) assays confirm the binding of BirA to the fur promoter. There is a negative correlation between $\mathrm{O} 157$ adherence and biotin concentrations in the small and large intestines of mice, and reduced O157 adherence is observed in mice fed a high-biotin diet. This regulatory pathway is present in an additional 19 EHEC strains but absent in 11 EPEC strains. We conclude that this regulatory pathway is used for the site-specific colonization of the large intestine by EHEC, and propose that biotin is potentially useful for the prevention of EHEC infection.

\section{Results}

O157 adheres to HeLa epithelial cells better than 055 . HeLa infection experiments were carried out to compare the adherence abilities of O157 and O55 by incubating log-phase Dulbecco's modified Eagle medium (DMEM)-grown bacterial cells with HeLa epithelial cells for $6 \mathrm{~h}$. These assays were assessed at hourly intervals, and it was found that the number of HeLa-attached O157 cells was 1.92-9.20 times higher compared with O55, with the largest difference being observed at $3 \mathrm{~h}$ (Fig. 1a). The two strains exhibited similar growth rates in DMEM (Fig. 1b), and the total numbers of attached and non-attached cells were also similar between the two strains during the 6-h course of the infection (Supplementary Fig. 1), indicating that the increase in the number of O157 cells adhering to HeLa cells was not due to different growth rates. Because both strains resumed growth after $4 \mathrm{~h}$ of infection into HeLa cells, as indicated by the rapid increase in the total number of cells (Supplementary Fig. 1), a 3-h 
incubation period was selected as the optimal attachment time for transcriptome analysis and subsequent adherence assays.

Transcriptional analysis of HeLa-attached 0157 and 055. To investigate the molecular basis of the different adherence characteristics of $\mathrm{O} 157$ and $\mathrm{O} 55$, transcriptome analyses were carried out to reveal differences in global gene expression profiles between HeLa-attached O157 and O55 cells (DMEM-grown cells incubated with HeLa cells for $3 \mathrm{~h}$ ) in comparison with free-living DMEM-grown cells. In total, 11,822,200-26,056,440 raw reads from different control and experimental groups were generated using

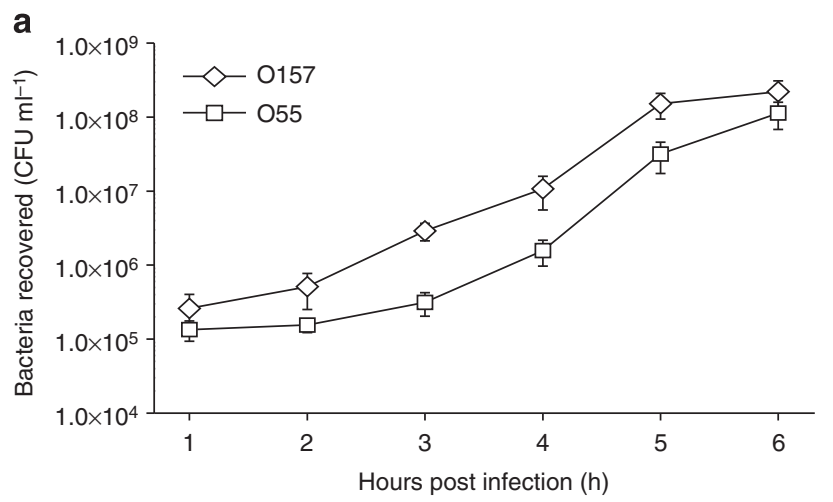

b

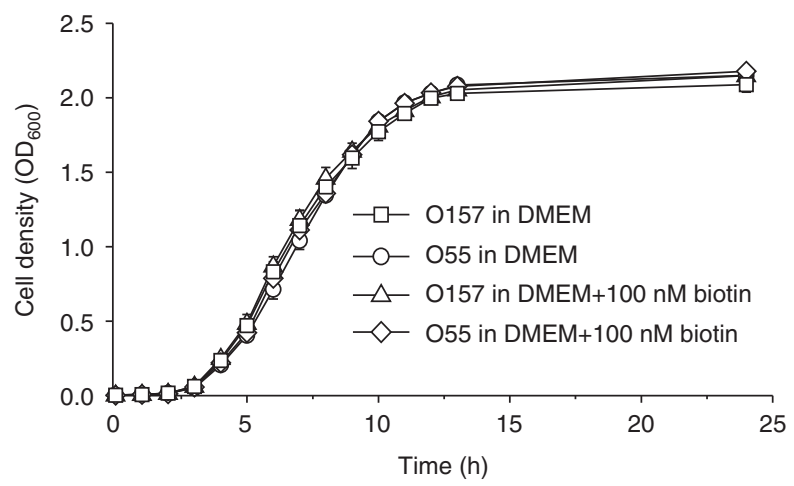

Figure 1 | The adherence and growth of 0157 and 055 in vitro. (a) The numbers of 0157 and 055 cells recovered at 1-6h post infection of HeLa epithelial cells. (b) The growth of 0157 and 055 in DMEM supplemented with 0 or $100 \mathrm{nM}$ biotin. Data are presented as means \pm s.d.; $n=3$.
Solexa/Illumina RNA-seq deep-sequencing analysis. After lowquality reads were removed, 10,599,805-23,525,548 reads from each library were considered for further analysis. There were 5,084,499 and 7,979,625 reads mapped to the host-cell genome in HeLaattached $\mathrm{O} 157$ and HeLa-attached O55, respectively. The total number of reads mapped to the E. coli O157:H7 EDL933 genome and the E. coli O55:H7 CB9615 genome ranged from 1,347,940 to $20,979,282$, and the mapping success rate was between $13.70 \%$ and 94.34\% (Supplementary Table 1). A total of 5,397 genes were detected in O157 and 5,121 in O55, of which 4,194 were conserved in both strains. The differentially expressed genes in HeLa-attached O157 and O55 compared with DMEM-grown bacteria are shown in Supplementary Fig. 2. The changes in the expression of the conserved genes were also compared. The expression levels of 1,069 genes were either upregulated (517) or downregulated (552) in both HeLa-attached O157 and O55 (Supplementary Data 1). Of these genes, many virulence genes related to the initial stage of infection that are shared between the two strains, including LEE genes and other adhesin genes, showed similarly altered expression (Supplementary Data 2), which is expected, as both EHEC and EPEC utilize the same infection mechanism. Notably, the expression of LEE genes in both strains was sharply decreased (Supplementary Data 2). Verification through qRT-PCR revealed that the expression of LEE genes in both O157 and O55 was significantly increased in the first $2 \mathrm{~h}$ of infection, whereas it was almost completely inhibited from $3 \mathrm{~h}$ onwards (Supplementary Fig. 3a,b). This result is in agreement with previous findings showing that LEE genes are induced in the early phase of infection to promote adherence, then inhibited in the late phase after colonization is established as an energy-saving strategy ${ }^{27,28}$.

In contrast, the expression of 1,243 conserved genes was either altered in only one strain or showed opposite patterns in the two strains (Supplementary Data 1); these genes might be related to the different virulence features of the strains. Of particular interest, the transcription levels of all essential genes involved in biotin synthesis (bioBFCD operon and bioA) were significantly upregulated (5.70-33.43-fold) in HeLa-attached O157 but remained unchanged in HeLa-attached O55. This result was confirmed via qRT-PCR (Table 1). However, the transcription levels of $a c c A, a c c B, a c c C$ and $a c c D$, encoding the biotindependent carboxylase (the only enzyme that requires biotin for its function in E. coli), were unchanged in both O157 and O55 (Table 1). Therefore, the upregulation of biotin synthesis in HeLa-associated $\mathrm{O} 157$ is unlikely to be related to the general metabolism of the bacteria, but rather, to a regulatory function related to adherence (see below).

Table 1 | Relative fold changes in the expression of biotin-related genes in 0157 and 055 after $3 \mathrm{~h}$ of incubation with HeLa cells.

\begin{tabular}{|c|c|c|c|c|c|c|c|}
\hline \multirow[t]{2}{*}{ Gene } & \multirow[t]{2}{*}{ Product/function } & \multicolumn{3}{|c|}{ Fold change in 0157} & \multicolumn{3}{|c|}{ Fold change in 055} \\
\hline & & Fold ${ }^{\star}$ & P value & Fold ${ }^{\dagger}$ & Fold $^{\star}$ & P value & Fold ${ }^{\dagger}$ \\
\hline bioA & Adenosylmethionine-8-amino-7-oxononanoate transaminase & 11.30 & $1.95 \times 10^{-4}$ & $10.97 \pm 1.05$ & 1.26 & 0.99 & $1.23 \pm 0.42$ \\
\hline bioB & Biotin synthase & 13.24 & $4.92 \times 10^{-6}$ & $3.43 \pm 0.29$ & -1.86 & 0.11 & $0.87 \pm 0.21$ \\
\hline bioC & Biotin biosynthesis protein BioC & 33.43 & $1.10 \times 10^{-6}$ & $6.01 \pm 1.22$ & 1.30 & 0.97 & $0.88 \pm 0.19$ \\
\hline bio $D$ & Dithiobiotin synthetase & 5.70 & $3.89 \times 10^{-3}$ & $5.63 \pm 2.24$ & ND & ND & $1.26 \pm 0.37$ \\
\hline biof & 8-Amino-7-oxononanoate synthase & 9.30 & $3.88 \times 10^{-4}$ & $4.28 \pm 0.65$ & ND & ND & $1.07 \pm 0.69$ \\
\hline $\operatorname{acc} A$ & Acetyl-CoA carboxylase carboxyltransferase subunit alpha & 1.34 & 0.78 & $1.47 \pm 0.43$ & 2.12 & 0.39 & $1.20 \pm 0.32$ \\
\hline$a c c B$ & Acetyl-CoA carboxylase biotin carboxyl carrier protein subunit & -1.00 & 0.73 & $1.17 \pm 0.13$ & 1.18 & 0.70 & $1.09 \pm 0.47$ \\
\hline $\operatorname{accC}$ & Acetyl-CoA carboxylase biotin carboxylase subunit & 1.30 & 0.83 & $1.06 \pm 0.28$ & 1.16 & 0.69 & $0.91 \pm 0.26$ \\
\hline$a c c D$ & Acetyl-CoA carboxylase subunit beta & 1.80 & 0.38 & $0.78 \pm 0.21$ & 1.84 & 0.61 & $0.86 \pm 0.22$ \\
\hline \multicolumn{8}{|c|}{$\begin{array}{l}\text { ND, not determined; - }- \text {, downregulated. } \\
P \text { values were calculated using binomial test. } \\
{ }^{*} \text { Fold change measured via RNA-Seq. } \\
\dagger \text { Fold change measured via } \text { QRT-PCR, the presented values are the mean } \pm \text { s.d. of three independent experiments. }\end{array}$} \\
\hline
\end{tabular}


Biotin inhibits 0157 adherence by controlling LEE genes. To further investigate whether biotin regulates O157 adherence, HeLa infection experiments were carried out in DMEM (biotinfree) supplemented with different concentrations of biotin. It was found that $\mathrm{O} 157$ adherence to HeLa cells was not affected by the presence of low levels of biotin (less than $50 \mathrm{nM}$ ) but decreased in the presence of high levels of biotin (above $100 \mathrm{nM}$; Fig. 2a). The same result was also obtained when Caco-2 intestinal epithelial cells were used instead of HeLa cells (Supplementary Fig. 4). The growth of $\mathrm{O} 157$ and O55 in DMEM was not affected by the presence of biotin $(100 \mathrm{nM}$; Fig. $1 \mathrm{~b})$, indicating that the negative effect of biotin on O157 adherence was not due to different growth rates. The expression of representative LEE genes, including ler (the master regulator of LEE genes), escT (LEE1), $e s c C$ (LEE2), escN (LEE3), eae (intimin, LEE5), tir (intimin receptor, LEE 5) and $\operatorname{esp} B$ (LEE 4), was significantly reduced in the presence of high levels of biotin $(100 \mathrm{nM})$ in O157, in comparison with the expression levels observed at $0 \mathrm{nM}$ biotin (Fig. 2b). This result indicates that the negative effect of biotin on O157 adherence was due to the negative regulation of LEE genes by biotin. In contrast, the ability of O55 to adhere to HeLa or Caco-2 cells and express LEE genes were unaffected by the presence of biotin (Fig. 2c,d and Supplementary Fig. 4).

BirA mediates biotin-induced 0157 LEE gene repression. In E. coli, BirA is able to sense a high biotin status and repress the expression of biotin synthesis genes ${ }^{20}$. This ability was confirmed for both $\mathrm{O} 157$ and $\mathrm{O} 55$ by showing that the expression of bir $A$ increased, whereas the expression of bio $A$ and bio $B$ decreased in the presence of $100 \mathrm{nM}$ biotin (Fig. 3a). Whether BirA is also involved in the biotin-induced repression of LEE genes in $\mathrm{O} 157$ was subsequently examined. Inactivation of birA in $\mathrm{O} 157$ resulted in an enhanced adherence capacity (Fig. 3b) and increased a

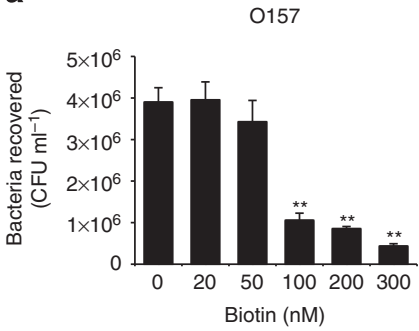

C

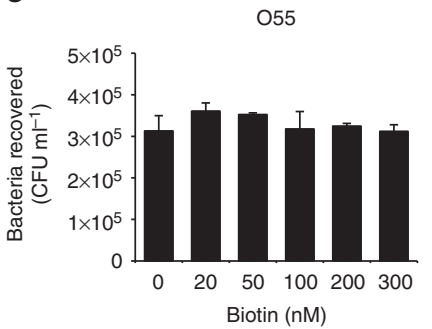

b

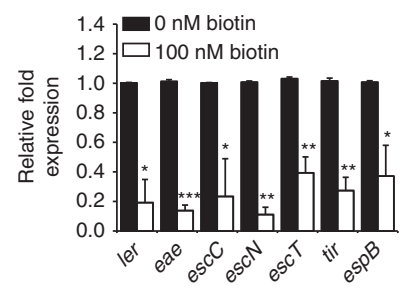

d

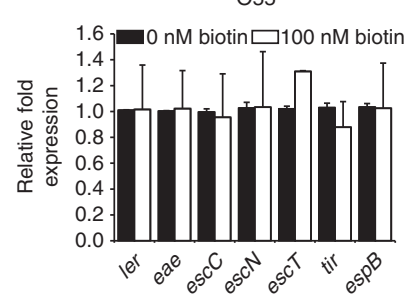

Figure 2 | The effect of biotin on the bacterial adherence capacity and LEE gene expression. (a) Adhesion of 0157 to HeLa cells in DMEM supplemented with different concentrations of biotin. (b) qRT-PCR was performed to measure the expression of LEE genes in 0157 grown in DMEM supplemented with 0 or $100 \mathrm{nM}$ biotin. (c) Adhesion of 055 to HeLa cells in DMEM supplemented with different concentrations of biotin. (d) qRT-PCR was used to measure the expression of LEE genes in O55 grown in DMEM supplemented with 0 or $100 \mathrm{nM}$ biotin. Data are presented as means \pm s.d.; $n=3$. ${ }^{\star} P \leq 0.05$; ${ }^{\star \star} P \leq 0.01 ;{ }^{\star \star \star} P \leq 0.001$. All $P$ values were calculated using Student's $t$-test. expression of LEE genes (Fig. 3c), and neither feature was affected by the presence of high levels of biotin (Fig. 3d,e). These changes could be restored to wild-type levels when a low-copy plasmid carrying the birA gene was introduced into the O157- $\Delta$ birA mutant strain (Fig. 3b,c), and overexpressing birA in O157 resulted in decreased bacterial adherence capacity (Fig. 3b) and LEE gene transcript levels (Fig. 3c). In contrast, inactivation of birA in $\mathrm{O} 55$ had no effect on bacterial adherence capacity, LEE gene transcription (Fig. 3f,g). Western blotting also revealed that the protein levels of intimin (encoded by eae) and its receptor, Tir, were significantly increased in the O157- $\Delta$ birA mutant strain compared with the O157 wild-type (WT) and complemented strains, whereas they remained unchanged in the O55- $\Delta$ birA mutant (Fig. 3h). These results confirmed that BirA acts as a negative LEE regulator in O157, but not in O55, and showed that the negative effect of biotin on O157 LEE genes is mediated by BirA.

The O157 genome was screened via ChIP-Seq analysis to reveal possible BirA-binding sites for the repression of LEE genes. A total of 6,591,200 and 6,011,222 raw reads were generated from the ChIP samples and mock ChIP samples. After low-quality reads were removed, the remaining 5,667,307 and 5,287,678 treated reads were mapped to the E. coli O157:H7 EDL933 genome. The number of uniquely mapped reads with no more than two mismatches from each library ranged from 4,669,886 to $5,091,616$, yielding between $72.52 \times$ and $79.22 \times$ coverage of the reference genomes (Supplementary Table 2). Because of the depth of coverage, we used a low false discovery rate cutoff of $0.001 \%$ and a threefold enrichment to call BirA ChIP peaks. In addition to the known bioO site, 55 potential BirA-binding sites were identified, and 8 representatives were confirmed through ChIPqPCR analysis (Supplementary Data 3). The presence of a large number of binding sites indicates that BirA plays multiple regulatory roles. However, no BirA-binding sites were found within the LEE region, indicating indirect regulation of LEE genes by BirA.

Fur mediates the regulation of 0157 LEE genes by BirA. Among the novel BirA-binding sites confirmed via ChIP-qPCR, one site was within the promoter region of fur (site 10 in Supplementary Data 3), which is a well-known global regulator ${ }^{29}$. The EMSAs and competition assays with O157 revealed that BirA binds specifically to the fur promoter and bioO (positive control), but not to rpoS (negative control) (Fig. 4a,c,d). The specific binding of BirA to the fur promoter was also observed in $\mathrm{O} 55$ (Fig. 4b). It was found that deletion of fur significantly reduced the ability of both $\mathrm{O} 157$ and O55 to adhere to HeLa cells and express LEE genes, and the ability to adhere could be restored to WT levels upon complementation with a functional copy of fur (Fig. $5 \mathrm{a}$ to $\mathrm{c}$ ). These result indicated that Fur is a positive regulator of LEE genes in both strains. Although six putative Furbinding sites (Supplementary Table 3) were identified within the O157 LEE region using bioinformatics, none were bound by Fur either in vivo, as indicated by ChIP-qPCR or in vitro in EMSAs; whereas Fur could bind to the fepA promoter (positive control) but not rpoS (negative control; Supplementary Table 3 and Supplementary Fig. 5), suggesting that the regulatory effect of Fur on LEE genes is indirect, which is also expected for O55 because the two strains share an identical LEE region. The lack of Fur binding to the promoter regions of other regulators involved in LEE regulation, including hns, fis, ihf $A$, ihfB, grlAR, grvA, qseA, hha, gadE, $h f q$, etrA, eivF, rpoN and rpoS, was also indicated through ChIP-qPCR (Supplementary Table 3). The regulator(s) of the indirect activation of LEE genes by Fur remains to be identified. 
a

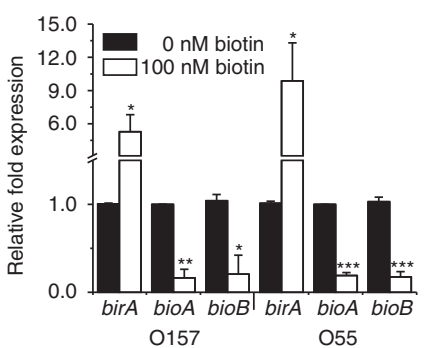

e

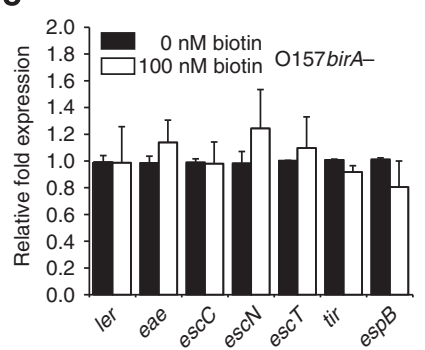

b

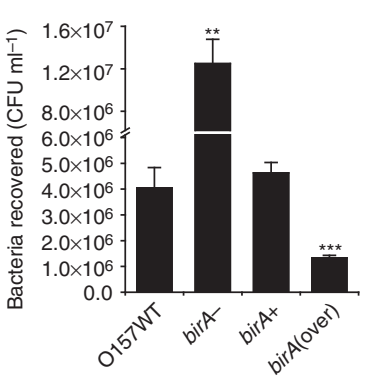

f

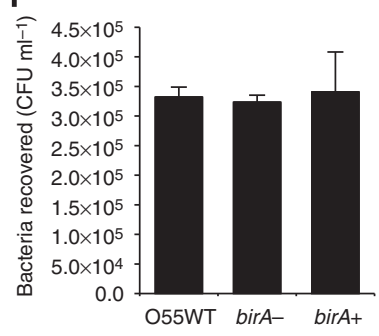

C

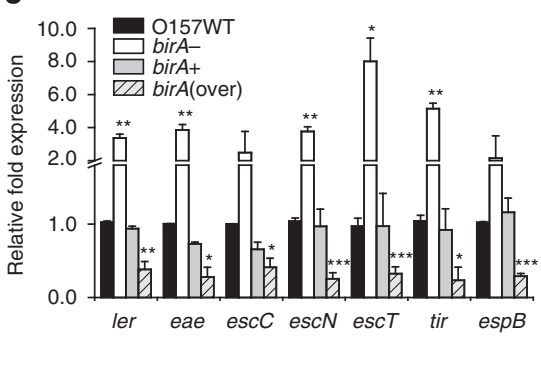

g

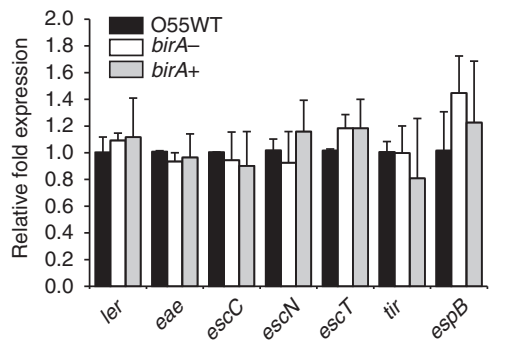

\section{d}

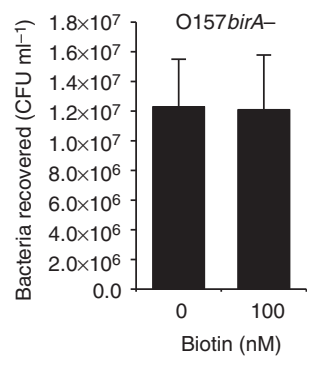

h

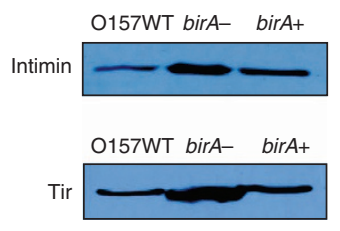

Figure 3 | The effect of birA on the bacterial adherence capacity and the expression of biotin synthetic genes and LEE genes. (a) qRT-PCR quantification of changes in the expression of birA, bioA and bioB in 0157 and $\mathrm{O} 55$ grown in DMEM supplemented with 0 or $100 \mathrm{nM}$ biotin. (b) Adhesion of O157 WT, birA-, birA + and birA(over) to HeLa cells. (c) qRT-PCR quantification of changes in the expression of LEE genes in O157 WT, birA-, birA + and birA(over). (d) Adhesion of the 0157 birA- strain to HeLa cells in DMEM supplemented with 0 or $100 \mathrm{nM}$ biotin. (e) qRT-PCR quantification of the change in LEE gene expression in 0157 birA- grown in DMEM supplemented with 0 or $100 \mathrm{nM}$ biotin. (f) Adhesion of O55 WT, birA- and birA + to HeLa cells. (g) qRT-PCR was performed to measure the expression of LEE genes in O55 WT, birA- and birA +. (h) Immunoblot analysis of intimin and its receptor, Tir, in O157 WT, birA- and birA + . Full blots are shown in Supplementary Fig. 9. birA-, birA mutant; birA +, birA-complemented strain; birA(over), birA-overexpression strain; WT, wild-type strain. Data are presented as means \pm s.d.; $n=3$. ${ }^{\star} P \leq 0.05 ;{ }^{\star \star} P \leq 0.01 ;{ }^{\star \star \star} P \leq 0.001$. All $P$ values were calculated using Student's $t$-test.

a

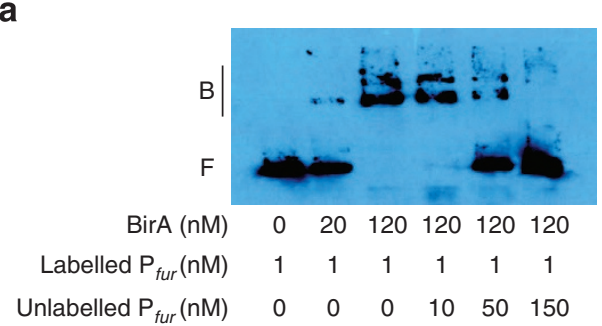

C

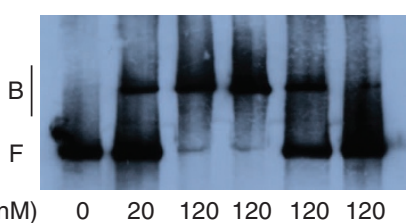

b

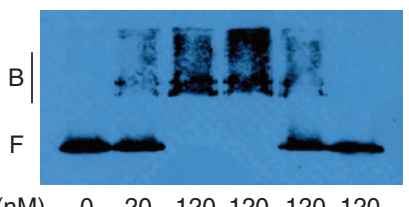

$\begin{array}{lllllll}\text { Labelled } \mathrm{P}_{\text {fur }}(\mathrm{nM}) & 1 & 1 & 1 & 1 & 1 & 1\end{array}$

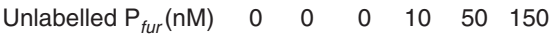

d

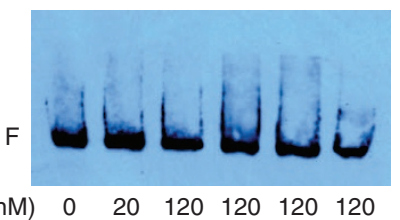

$\begin{array}{lllllll}\operatorname{BirA}(n M) & 0 & 20 & 120 & 120 & 120 & 120\end{array}$

Labelled rpos (nM) $\quad 1 \quad 1 \quad \begin{array}{lllll}1 & 1 & 1 & 1\end{array}$

Unlabelled rpoS (nM) $\quad 0 \quad 0 \quad 0 \quad 10 \quad 50 \quad 150$

Figure 4 | EMSAs and competition assays reveal the specific binding of BirA to the promoter region of fur in vitro for both 0157 and 055 . (a) 0157 , (b) O55, (c) positive control (bioO), (d) negative control (rpoS). The positions of the bound (denoted with ' $\mathrm{B}$ ') and free (denoted with ' $\mathrm{F}$ ') probe are shown on the left, and the concentrations of the probe and purified BirA are indicated at the bottom of each lane. Full blots are shown in Supplementary Fig. 10.

Additional in vitro experiments showed that both the transcription level and protein level of fur were significantly increased in the O157- $\Delta$ birA mutant, and both values could be restored to wild-type levels when a low-copy plasmid carrying the birA gene was introduced into the O157- $\Delta$ birA mutant (Fig. 5d,e). These results confirmed that BirA is a negative regulator of fur. Although the transcript level of fur in the $\mathrm{O} 157$ WT strain was significantly reduced by the presence of a high concentration of biotin $(100 \mathrm{nM})$, the presence of biotin had no obvious effect on the expression of fur in the O157- $\Delta$ birA mutant (Fig. 5f). Neither the adherence capacity nor LEE gene expression of the O157- $\Delta$ fur mutant was affected by the presence of biotin 


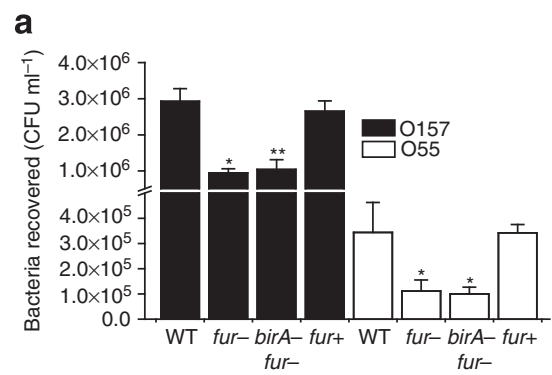

b

d

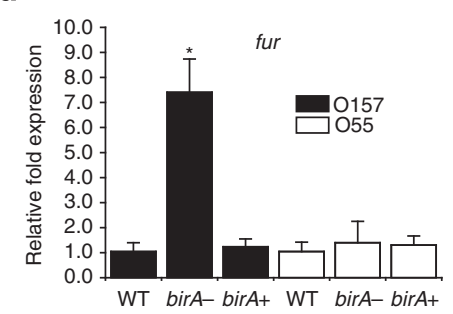

e

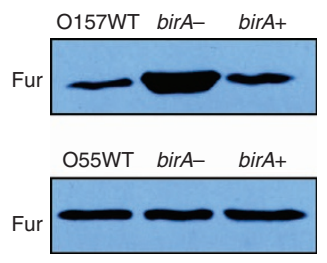

h

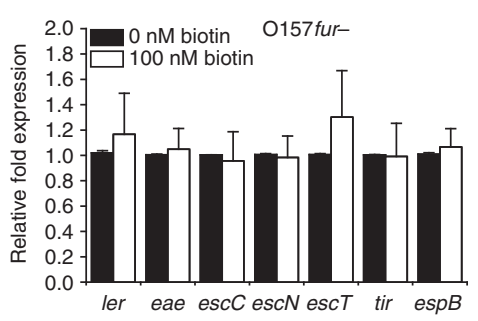

f

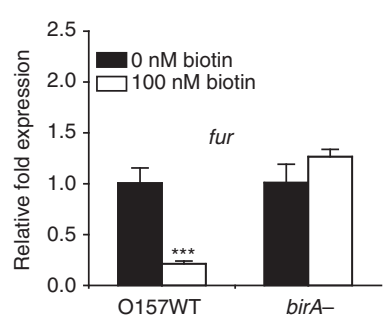

C

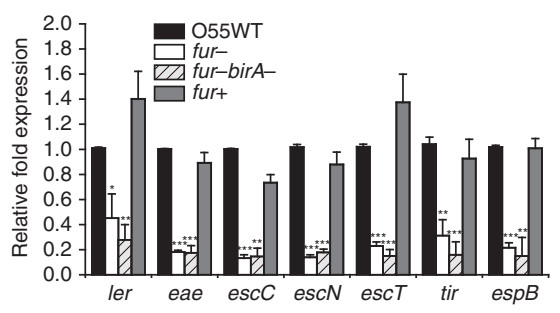

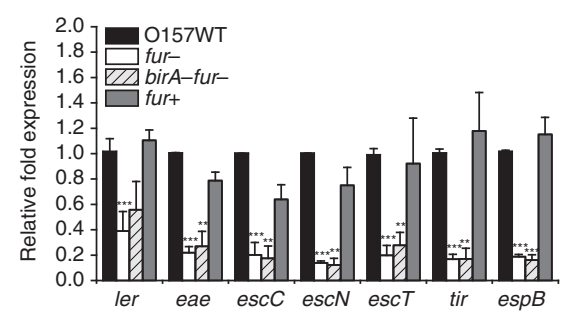

g

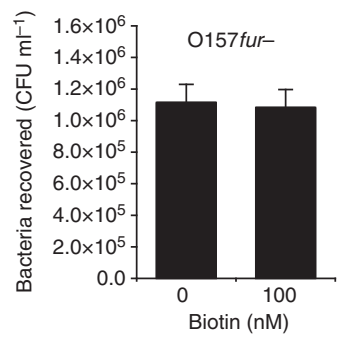

i

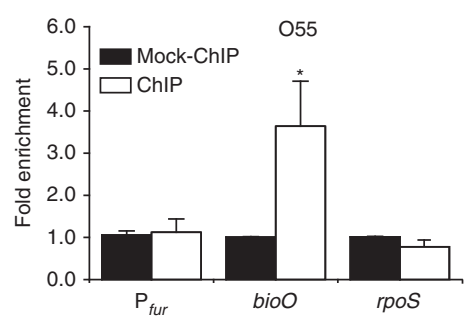

Figure 5 | The regulation of adherence and LEE genes by BirA is mediated by fur in 0157. (a) Adhesion of O157 and O55 WT, fur-, fur-birA- and fur + to HeLa cells. (b) LEE gene transcript levels in O157 WT, fur-, fur-birA- and fur +. (c) LEE gene transcript levels in O55 WT, fur-, fur-birA- and fur +. (d) qRT-PCR quantification of changes in the expression of fur in 0157 and 055 WT, birA- and birA +. (e) Immunoblot analysis of Fur in O157 and O55 WT, birA- and birA + . Full blot is shown in Supplementary Fig. 9. (f) qRT-PCR quantification of the change in expression of fur in O157 WT and birA- grown in DMEM supplemented with 0 or $100 \mathrm{nM}$ biotin. (g) Adhesion of the 0157 fur- to HeLa cells in DMEM supplemented with 0 or $100 \mathrm{nM}$ biotin. (h) qRT-PCR quantification of the change in expression of LEE genes in the 0157 fur- grown in DMEM supplemented with 0 or $100 \mathrm{nM}$ biotin. (i) Fold enrichment of the fur promoter in $\mathrm{O} 55 \mathrm{ChIP}$ samples, as measured via ChIP-qPCR. bioO and rpoS are positive and negative controls, respectively. birA-, birA mutant; birA +, birA-complemented strain; fur-, fur mutant; fur-birA-, fur birA double mutant; fur +, fur-complemented strain; WT, wild-type strain. Data are presented as means \pm s.d.; $n=3$. ${ }^{\star} P \leq 0.05 ;{ }^{\star \star} P \leq 0.01 ;{ }^{\star \star \star} P \leq 0.001$. All $P$ values were calculated using Student's $t$-test.

(Fig. 5g,h), indicating that Fur is required in this biotin signalling virulence regulatory pathway. Furthermore, the observed adherence ability and the transcription levels of LEE genes were similar in the O157- $\Delta$ fur mutant and the O157- $\Delta$ fur $\Delta$ birA double mutant (Fig. 5a,b), indicating that the regulatory role of BirA on adherence and LEE gene expression in O157 is mediated by Fur.

Although the promoter region of fur in $\mathrm{O} 55$ is identical to that in O157, BirA is unable to bind to this region, as indicated through ChIP-qPCR analysis (Fig. 5i). The expression of fur at both the transcriptional and protein levels was also not affected by mutating birA in O55 (Fig. 5d,e and Supplementary Fig. 6), indicating that BirA shows no regulatory role in relation to fur in O55. It is possible that BirA access to the fur-binding site is prevented in $\mathrm{O} 55$ by the occupation of that region by other regulators.

Negative effect of biotin on 0157 adherence in mice. The effect of the biotin status of the host intestinal tract on $\mathrm{O} 157$ adherence was investigated using BALB/c mice maintained on a normal diet (standard mouse feed and sterilized water) or a biotin-rich diet (standard mouse feed and sterilized water containing $10 \mathrm{mM}$ biotin) for 7 days. Under the normal diet, the number of bacteria that adhered to the colon $\left(5.19 \times 10^{7}\right.$ colony-forming units (CFU) per gram $\left(\mathrm{CFUg}^{-1}\right)$ tissue) was 31.5 -fold higher than the number that adhered to the ileum $\left(1.65 \times 10^{6} \mathrm{CFU} \mathrm{g}^{-1}\right.$ tissue; Fig. 6a), as expected. The biotin level in the ileal contents (538.6 pmol g $^{-1}$ luminal content) was 14.3 -fold higher than in the colonic contents $\left(37.7 \mathrm{pmolg}^{-1}\right.$ luminal content; Fig. 6b). Under the biotin-rich diet, a similar difference in adherence was observed between the colon and ileum (Fig. 6a). However, the number of bacteria that adhered was 8.0 times (colon) and 4.4 times (ileum) lower than the number obtained from the same sites under the normal diet, whereas the biotin levels were increased 14.7 and 4.0 times in the respective luminal contents (Fig. 6a,b). Therefore, O157 adherence to the mouse intestinal tract was reduced by increased biotin levels in mice fed a highbiotin diet.

The molarity (nM) of biotin in mouse intestines was estimated based on the water content $(\mathrm{ml})$ obtained by oven drying at $105^{\circ} \mathrm{C}$ for $24 \mathrm{~h}$, and the quantity of biotin (pmol) per gram of luminal content. The concentration of biotin was found to be approximately $450-700 \mathrm{nM}$ in the ileal content (Supplementary Fig. 7); these concentrations are higher than the concentration $(100 \mathrm{nM})$ determined by an in vitro experiment to induce repression of LEE genes. The biotin concentration was found to 
a
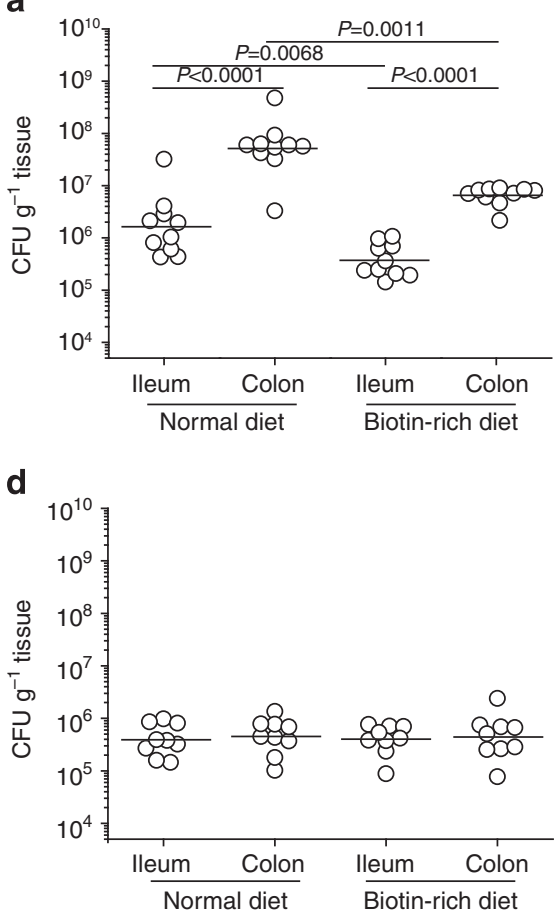

b

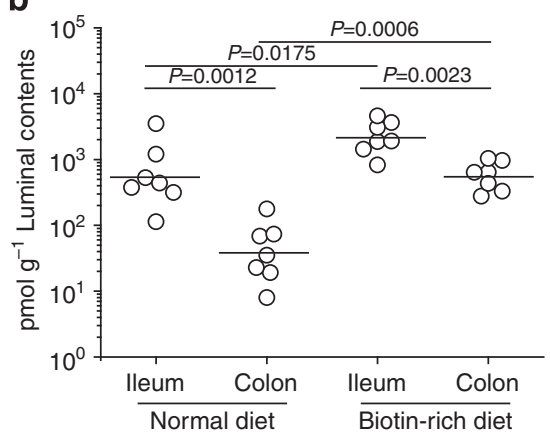

e

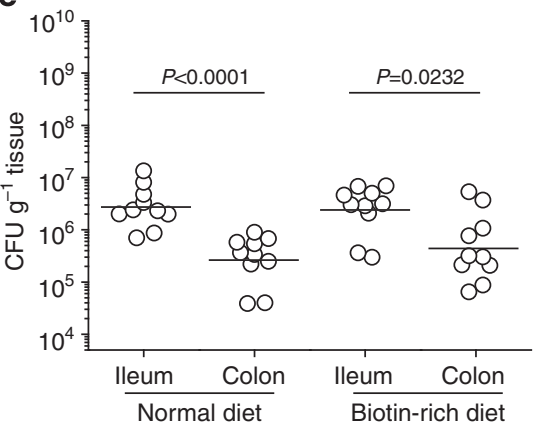

c

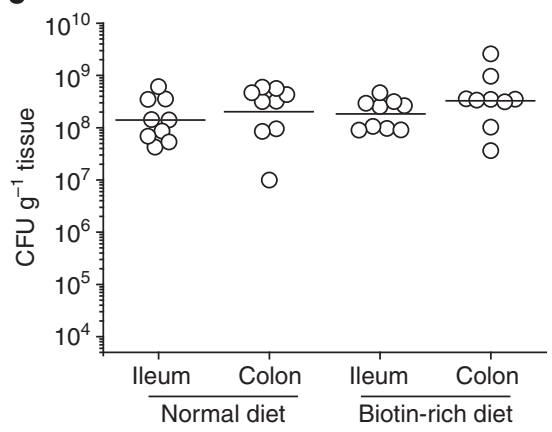

Figure 6 | The effect of biotin on bacterial adherence capacity in the mouse intestinal tract. (a) Determination of the adherence capacity of 0157 wildtype strain in the intestinal tract of mice maintained on a normal diet or a biotin-rich diet. (b) Quantification of biotin concentrations in the ileal contents and colonic contents obtained from mice fed a normal diet or biotin-rich diet. (c) Determination of the adherence capacity of the O157 birA mutant in the intestinal tract of mice maintained on either a normal diet or a biotin-rich diet. (d) Determination of the adherence capacity of the 0157 fur mutant in the intestinal tract of mice maintained on either a normal diet or a biotin-rich diet. (e) Determination of the adherence capacity of 055 wild-type strain in the intestinal tract of mice maintained on a normal or biotin-rich diet. Each graph represents a typical experiment, with 7-10 mice in each group; the horizontal lines represent the geometric means. Statistical significance was assessed via the Mann-Whitney rank-sum test.

be $30-45 \mathrm{nM}$ in the colonic content (Supplementary Fig. 7), which is less than the level for repression. Therefore, there was agreement between the in vivo and in vitro results for the levels of biotin that are required to induce repression.

The adherence of $\mathrm{O} 157$ to the mouse intestinal tract was enhanced by the deletion of birA and reduced by the deletion of fur, and the levels changed to a similar extent in mice fed either a normal diet or a biotin-rich diet (Fig. 6c,d), further confirming that the effect of biotin on $\mathrm{O} 157$ adherence is mediated by BirA and Fur. In contrast, the number of $\mathrm{O} 55$ that were recoverable from the mouse intestinal tract was much higher in the ileum $(2.73 \times$ $10^{6} \mathrm{CFU} \mathrm{g}^{-1}$ tissue $)$ than in the colon $\left(2.69 \times 10^{5} \mathrm{CFU} \mathrm{g}^{-1}\right.$ tissue $)$ under the normal diet, and the feeding mice a biotin-rich diet had no obvious effect on O55 adherence (Fig. 6e).

Negative effect of biotin on adherence is conserved in EHEC. The presence of the biotin signalling regulatory pathway for the control of bacterial adherence was investigated using an additional 19 representative EHEC strains from nine serotypes and 11 EPEC strains from eight serotypes (Supplementary Table 4), isolated from different parts of the world, by carrying out HeLa infection experiments in the presence of 0 and $100 \mathrm{nM}$ biotin. It was found that adherence to HeLa cells was significantly decreased in the presence of $100 \mathrm{nM}$ biotin for all 19 EHEC strains (Fig. 7a). In contrast, biotin status had no obvious influence on the adherence abilities of the 11 EPEC strains (Fig. 7b).

\section{Discussion}

The large intestine contains a high density of resident microflora, and pathogenic invaders must compete effectively for both limited nutrients and colonization sites ${ }^{30}$. To do so, EHEC has developed strategies for consuming mucus-derived carbohydrates more rapidly than the resident bacteria ${ }^{31}$ and for intimately adhering to host epithelial cells via the formation of $\mathrm{A} / \mathrm{E}$ lesions $5^{5}$. The adoption of this BirA-mediated biotin signalling regulatory pathway to control the expression of LEE genes allows EHEC to recognize the large intestine for adhesion. Thus, it is an important pathway for the evolution of this pathogen as an invader of the large intestine. Invading the large intestine rather than the small intestine is apparently a better option for survival because the latter site is more hostile due to its lower $\mathrm{pH}$, higher level of bile salts and more rapid movement of intestinal contents $^{32}$.

A model for this regulatory pathway in EHEC O157 is proposed (Fig. 8). Briefly, when the bacterium enters the small intestine, where the biotin level is high, the expression of BirA is upregulated, repressing the expression of fur. Consequently, the activation of LEE genes by Fur is inhibited, and adherence is therefore prevented. This allows the bacteria to bypass the small intestine and enter the large intestine. Because the biotin level is low in the large intestine, the expression of BirA is downregulated, and the repression of fur is removed, allowing the activation of LEE genes by Fur to promote adherence. This pathway is incomplete in O55 due to the lack of a Fur response to BirA. Although biotin acts as a negative signalling molecule for EHEC adherence in the large intestine, the presence of other signals for EPEC adherence in the small intestine is predicted, which remain to be investigated. However, it is clear that EPEC and EHEC use different regulatory mechanisms to control the expression of LEE genes, leading to pathotype-specific colonization of the small and large intestines, respectively. 
Current knowledge of the regulatory role of BirA is limited to the control of biotin synthesis associated with bacterial metabolism $^{20,22}$. Here, we demonstrated, for the first time, that BirA is also involved in the regulation of a non-biotin-related process, specifically EHEC adherence, through modulating the expression of LEE genes. In both types of processes, BirA senses biotin levels to regulate the expression of the relevant genes. In contrast to the direct regulation of the bio operon by BirA, the regulation of LEE genes by BirA is indirect and is mediated by Fur. Fur has been shown to both directly repress and indirectly activate genes in response to iron and/or other environmental stimuli $^{29}$. In EHEC, Fur is involved in the regulation of adhesin production, iron homeostasis, flagellum chemotaxis and acid and
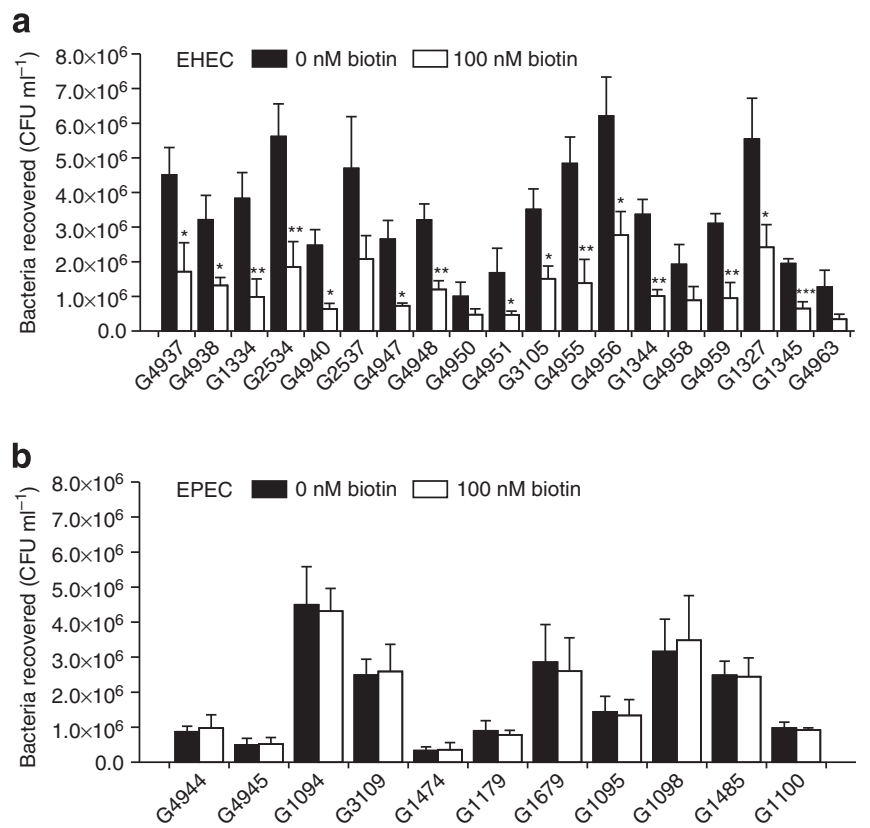

Figure 7 | The effect of biotin on the adherence capacity of other EHEC and EPEC strains. (a) 19 EHEC strains, (b) 11 EPEC strains. Data are presented as means \pm s.d.; $n=3$. ${ }^{\star} P \leq 0.05$; ${ }^{\star \star} P \leq 0.01 ;{ }^{\star \star \star} P \leq 0.001$. All $P$ values were calculated using Student's $t$-test. oxidative stresses ${ }^{29,33}$. Therefore, by interfering with Fur, BirA is able to affect other Fur-regulated virulence genes as well. More significantly, the regulatory role of BirA goes beyond its interaction with Fur, as we identified a large number of BirAbinding sites in the $\mathrm{O} 157$ genome. Collectively, these findings indicate that BirA is not only a specific regulator of biotin-related processes but also a global regulator that impacts many other functions.

Unfortunately, we were unable to elucidate the exact mechanism behind the regulatory role of Fur on O157 LEE gene expression and adherence. In addition to LEE genes, we also examined the possible regulatory role of Fur on other known adherence related genes reported in $\mathrm{O} 157$ and O55, including Efal adhesins (z4332), long polar fimbria (z4971, z5225), F9 fimbrial adhesin (z2200-z2203) and Paa adhesin (z2053), as well as $f l h D C$, the Fur-regulated flagellar regulatory genes predicted in silico $^{34}$, and two representative flagellum synthetic genes (flgM and $\mathrm{fliC}$ ) by mutation and qRT-PCR analysis. However, none of these genes were found to be regulated by Fur (Supplementary Fig. 8). On the other hand, we also investigated known Furregulated LEE regulators, including the positive LEE regulators $\operatorname{rpoS}^{35}$ and $h n s^{14}$, as well as the negative regulators $f i s^{36}$ and $r p o N^{37}$. However, none of these LEE regulators were found to be directly regulated by Fur as indicated by ChIP-qPCR analysis (Supplementary Table 3). We propose that the regulatory role of Fur on LEE genes could be indirectly mediated by those four regulators, although the presence of other Fur-regulated LEE regulators is also possible.

As expected, the expression of fur was induced at an early stage of HeLa infection and inhibited in the later stages, along with the expression of LEE genes, in the absence of external biotin (Supplementary Fig. 3c), indicating the presence of another fur regulator, most likely an activator. This activator must bind to the promoter region of fur to activate the gene. Some BirA can likely be sequestered from the bioO site to bind to the fur site when the bound activator is removed to inactivate fur, resulting in partial de-repression of the bio operon, explaining the increase in biotin synthesis observed in the late infection phase in O157. Therefore, BirA may also play a role in the repression of fur in the late infection stage of $\mathrm{O} 157$ in the absence of external biotin. The nature of the fur activator remains to be investigated. However, the identification of this novel regulatory pathway for LEE genes in $\mathrm{O} 157$ cannot explain the enhanced adherence of O157 to HeLa

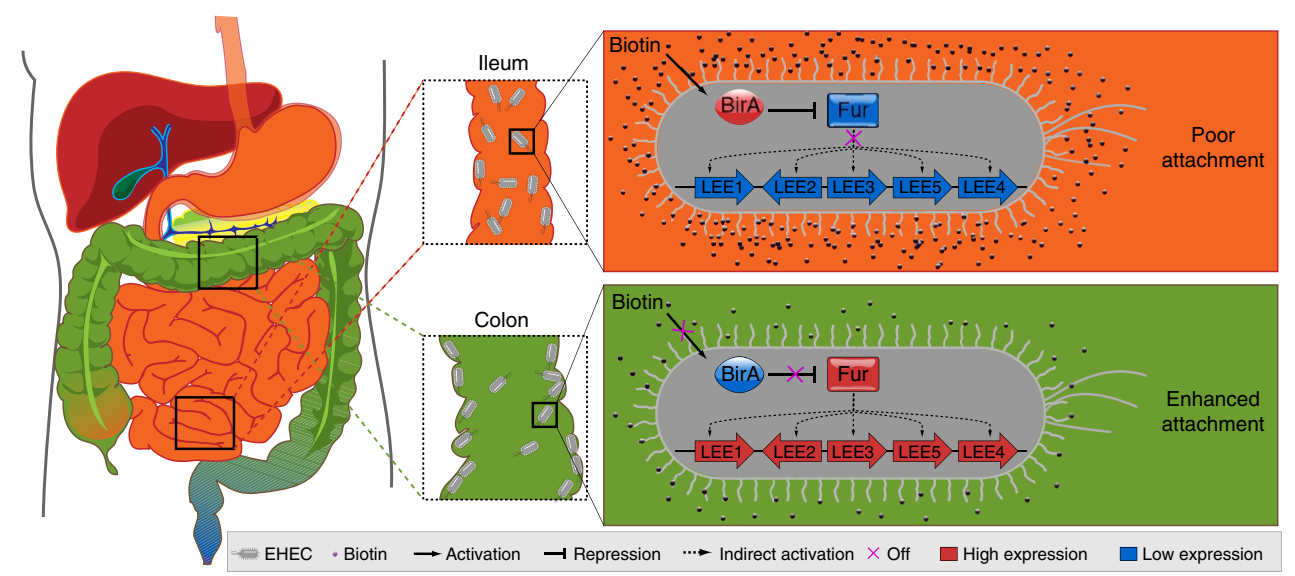

Figure 8 | Model for the regulation of EHEC adherence by biotin in the human intestine. In the small intestine, the biotin level is high, and the expression of BirA is upregulated, repressing the expression of fur. The activation of LEE genes is inhibited, and adherence is therefore prevented. In the large intestine, the biotin level is low, and the expression of BirA is downregulated. The repression of fur is removed, allowing the activation of LEE genes by Fur to promote adherence. 
cells detected in the absence of external biotin, despite this observation being the initial driver of this study. More information is needed to clarify this point.

The weaker adherence to HeLa cells by DMEM-grown O55 compared with DMEM-grown O157 in the absence of biotin was apparently not related to biotin. Typical EPEC strains containing the EAF (EPEC adherence factor) plasmid usually have greater adherence abilities than atypical strains without the plasmid ${ }^{38}$. O55 is an atypical EPEC, which is likely to be one factor explaining its weaker adherence.

The number of sequencing reads mapped to the bacterial genome is lower in HeLa-attached O157 (4.92 M) and HeLaattached O55 $(1.35 \mathrm{M})$ compared with DMEM-grown samples (Supplementary Table 1); this difference could be a result of inefficient deletion of host-cell RNA from total RNA samples during library construction. However, the rates (\%) of gene coverage by the sequencing reads were $87.92 \%$ in HeLa-attached $\mathrm{O} 157$ and $79.52 \%$ in HeLa-attached O55 (Supplementary Table 1). These values are within the range (70-95\%) reported previously for bacterial transcriptome studies ${ }^{39-41}$. Although some of the differentially expressed genes might be missed and some values for the differences might be less accurate, the conclusions drawn in this study are not affected because all of the necessary genes involved in this regulatory pathway were further verified using qRT-PCR (Table 1 and Supplementary Fig. 3).

Both streptomycin mouse models and conventional mouse models have been widely used to investigate the adherence and pathogenesis of intestinal pathogens ${ }^{42}$. Colonization resistance is absent in streptomycin mice due to the lack of normal bowel flora, and this model is best suited to evaluating the relative colonization capacity of different strains via competitive infection studies (co-inoculated). In the present study, a conventional mouse model with an intact intestinal flora, which better reflects the typical gastrointestinal environment to which intestinal pathogens are exposed following ingestion, was used to examine the effect of biotin on the adherence capacity of EHEC and EPEC in vivo. Although this model require a high infection dose $\left(10^{9}\right.$ $\mathrm{CFU}$ ), our results clearly indicated that biotin represses only the adherence of $\mathrm{O} 157$ in the mouse intestine and not that of $\mathrm{O} 55$.

Diarrhoeic diseases caused by EHEC are an important public health problem around the world. EHEC O157:H7 alone causes more than 73,000 illnesses, 2,100 hospitalizations and 60 deaths annually in the United States ${ }^{43}$. Several therapeutic strategies for diseases caused by EHEC have been developed, including the use of antibiotics and vaccination ${ }^{44,45}$. However, there is no established effective therapeutic strategy for treating EHEC infection and the use of antibiotics may be contraindicated, as bacterial lysis increases the release of Shiga $\operatorname{toxin}^{43}$. Our results revealed that high levels of biotin significantly reduced EHEC adherence in the mouse intestinal tract. Because biotin does not lyse cells and impose selection for resistance, it is attractive to propose the use of biotin as a potential antivirulence drug to prevent and control EHEC infection. For such applications, a slow-release form would ensure that the agent reaches the large intestine.

\section{Methods}

Bacterial strains, plasmids and growth conditions. The bacterial strains and plasmids used in this study are summarized in Supplementary Table 4 . There are approximately 20 EHEC serotypes and 15 EPEC serotypes that are most commonly associated with human diseases ${ }^{46,47}$. In this study, we used 19 EHEC strains from nine serotypes and 11 EPEC strains from eight serotypes. The nine EHEC serotypes were O157:H7, O157:H-, O26:H11, O26:H-, O103:H2, O111:H8, O111:H-,

O145:H28 and O70:H11, and the eight EPEC serotypes were O55:H7, O127:H-, O86:H34, O114:H2, O126:H-, O128:H2, O142:H6 and O145:H34. The strains were first verified through serotyping using polyclonal $\mathrm{O}$-antigen and $\mathrm{H}$-antigen antisera
} (Tianjin Biochip; \# IM-EH004 and IM-EH001). A multiplex PCR assay was then performed to confirm the presence of intimin and Shiga toxin genes following the method of the STEC center (http://www.shigatox.net/stec/cgi-bin/index). All of the EHEC strains used in this work contained the eae gene and at least one Shiga toxin gene, whereas all EPEC strains contained the eae gene but no Shiga toxin genes (see Supplementary Table 4 for details). Mutant strains were generated using the $\lambda$ Red recombinase system ${ }^{48,49}$, and all strains were verified via PCR amplification and sequencing. To avoid lethality, we constructed the birA mutant in the presence of a plasmid-borne birA sequence from Acinetobacter calcoaceticus, following the method of Chakravartty and Cronan ${ }^{50}$. This heterologous BirA provides full biotin ligase function but has no regulatory function because it lacks the DNA-binding domain $^{51}$. Complementary strains were constructed by cloning genes of interest into the pWSK129 or pTRC99A plasmid. The resulting constructs were then electroporated into the corresponding mutant strains. Strains for gene overexpression were constructed by cloning genes of interest into the pET28a expression vector; the resulting constructs were then electroporated into the $E$. coli BL21 strain. The primers used for the construction of the mutant strains and recombinant plasmids are described in Supplementary Table 5. All strains were maintained at $-80^{\circ} \mathrm{C}$ in Luria-Bertani (LB) broth with $20 \%$ glycerol and were grown overnight at $37^{\circ} \mathrm{C}$ in LB broth when required. As necessary, antibiotics were added at the following final concentrations: ampicillin, $100 \mathrm{mg} \mathrm{ml}^{-1}$; chloramphenicol, $15 \mathrm{mg} \mathrm{ml}^{-1}$; and kanamycin, $50 \mathrm{mg} \mathrm{ml}^{-1}$.

Sample preparation for RNA-Seq. HeLa cell infection was performed according to a previously described method with some modifications ${ }^{52,53}$. Briefly, HeLa cell cultures were grown at $37^{\circ} \mathrm{C}$ under $5 \% \mathrm{CO}_{2}$ until confluent. Three hours before infection, the HeLa cells were washed three times with pre-warmed phosphatebuffered saline (PBS), and the medium was replaced with fresh DMEM without antibiotics and fetal bovine serum. HeLa cell cultures were infected with exponential-phase O157 or O55 at a multiplicity of infection of 100:1 (refs 52,54) After co-culturing with HeLa cells for $3 \mathrm{~h}$, non-adherent bacteria were removed through extensive washing with pre-warmed PBS six times. The eukaryotic cells were lysed using lysis buffer (95\% ethanol, 5\% phenol and $0.1 \%$ SDS), and the adherent bacteria were collected as the experimental samples. As a control, logarithmic O157 or O55 was grown in fresh DMEM without HeLa cells for $3 \mathrm{~h}$, and the DMEM-grown cultures were collected as control samples. These pelleted bacterial cells were used directly for RNA extraction. The assays were performed in three independent experiments.

RNA preparation. Total RNA was isolated from samples using the TRIzol LS Reagent (Life; \#10296-028) according to the manufacturer's instructions. RNA samples were further purified using the RNeasy Mini Kit (Qiagen; \#74104) and were treated with RNase-Free DNase I (Qiagen; \#79254) to eliminate genomic DNA contamination. Host-cell RNA was depleted using the MICROBEnrich Kit (Ambion; \#AM1901), and bacterial 23S and 16S rRNAs were subsequently depleted with the MICROBExpress Bacterial mRNA Enrichment Kit (Ambion; \#AM1905) RNA quality was determined using a Bioanalyzer (Agilent), and its quantity was assessed using a NanoDrop spectrophotometer (Thermo) after each manipulation step.

RNA-Seq library construction and sequencing. The mRNA was fragmented using divalent cations under elevated temperatures. Random hexameric primers and the SuperScript Double-Stranded cDNA Synthesis Kit (Invitrogen; \#11917020) were used to synthesize double-stranded cDNA. The ends of these cDNA fragments were end repaired and A-tailed. The A-tailed fragments were then purified and ligated to Illumina adapters. These products were subsequently loaded into $2 \%$ low melting point agarose gels. The cDNA fragments between 200 and $250 \mathrm{bp}$ in size were selected and purified using the Qiaquick Gel Extraction kit (Qiagen; \#28704). After purification, a PCR assay using the obtained cDNA was performed, and the PCR products were purified using the Qiaquick PCR Purification Kit (Qiagen; \#28104). Cluster formation, primer hybridization and single-end 36-cycle sequencing was performed according to the manufacturers' recommended protocol. Three independent libraries were prepared for each of the RNA-Seq samples.

Read mapping and statistics. The quality of all raw reads was assessed using the FastQC quality control tool with the default parameters, and the low-quality reads (Phred quality scores $<20$ ) were discarded. The treated reads from different libraries were then mapped to the E. coli O157:H7 EDL933 genome (NC_002655) and the E. coli O55:H7 CB9615 genome (NC 013941) using the Burrows-Wheeler Aligner with the following parameters: [-l 32] [-k 2] [-M 3] [-O 11] [-E 4]. The coverage at each gene was calculated, and the RPKM (reads per kilobase of coding sequence per million reads) method was used to quantify gene expression levels. The genes showing an $\mathrm{RPKM} \geq 10$ were chosen for subsequent statistical analysis. In addition, genes that presented an RPMK $<10$ under one growth condition and an $R P K M \geq 10$ in the other condition were also accepted as candidates ${ }^{55}$. Differential gene expression was analyzed using the edgeR package ${ }^{56}$ with the default parameters. Genes exhibiting $P$ values $<0.05$ and a threefold or greater difference in RPKM between two conditions were defined as differentially expressed. 
Chromatin immunoprecipitation. ChIP was performed as previously described $^{57,58}$ with some modifications to the protocol. Inducible expression vectors carrying $3 \times$ FLAG-tagged birA or fur were constructed and transformed into corresponding mutant strains. The bacterial cultures were grown to midlogarithmic phase $\left(\mathrm{OD}_{600} \approx 0.4\right)$ and were induced with $1 \mathrm{mM}$ isopropyl- $\beta$-Dthiogalactoside for $30 \mathrm{~min}$ at $37^{\circ} \mathrm{C}$. To crosslink proteins to DNA, formaldehyde was added to a final concentration of $1 \%$, and the samples were incubated at room temperature for $25 \mathrm{~min}$. The cross-linking reaction was quenched by adding glycine to a final concentration of $0.5 \mathrm{M}$. The cross-linked cells were washed three times with ice-cold TBS and sonicated with 15 cycles of $30 \mathrm{~s}$ on/off at $95 \%$ power to generate DNA fragments of approximately $500 \mathrm{bp}$. Cell debris was removed, and the resulting supernatant was used as the cell extract for the immunoprecipitation of protein-DNA complexes using an anti-3 $\times$ FLAG antibody (Sigma; \#F1804) and protein A magnetic beads (Invitrogen; \#10002D) according to the manufacturer's instructions. As a negative control, chromatin immunoprecipitation was performed on the other aliquot without the addition of antibodies. The RNA in the DNA sample was removed via incubation with RNaseA for $2 \mathrm{~h}$ at $37^{\circ} \mathrm{C}$, and proteins were then removed by incubation with proteinase $\mathrm{K}$ for $2 \mathrm{~h}$ at $55^{\circ} \mathrm{C}$. The DNA sample was subsequently purified with a PCR purification kit (Qiagen; \#28104). All ChIP experiments were performed in three independent experiments.

CHIP-Seq library construction and sequencing. ChIP DNA and mock ChIP DNA were end repaired, A-tailed and ligated to Illumina adapters. Size selection was performed to obtain a library with a median length of approximately $250 \mathrm{bp}$. After purification, a PCR assay was performed using Illumina genomic DNA primers 1.1 and 2.1, with 18 cycles of amplification. Cluster formation, primer hybridization, and single-end 36 -cycle sequencing were performed according to the manufacturers' recommended protocol. Three independent libraries were prepared for each of ChIP-Seq samples.

Identification of protein-binding regions. The quality of the raw reads from the ChIP samples and mock ChIP samples was assessed using the FastQC quality control tool with the default parameters. The low-quality reads (Phred quality scores $<20$ ) were discarded. The treated reads were then aligned to the E. coli O157:H7 EDL933 reference genome allowing no more than two mismatches, using the Burrows-Wheeler Aligner with the following parameters: [-1 32] [-k 2] [-M 3] [-O 11] [-E 4]. The data file containing the genomic coordinates of the mapped reads was then transformed into BED file format. We applied a false discovery rate cutoff of 0.001 to identify BirA ChIP peaks using Site Identification from Short Sequence Reads ${ }^{59}$ with the following parameters: [-D 0.001] [-m 0.8] [-w 20] [-E 2]. Peaks identified by Site Identification from Short Sequence Reads with a relative enrichment of more than threefold were scored as potential BirA-binding sites.

Bacterial adherence assays. Adherence assays were performed using a previously described method ${ }^{60}$. HeLa cells and Caco-2 cells were purchased from the Shanghai Institute of Biochemistry and Cell Biology of the Chinese Academy of Sciences (Shanghai, China). Before infection, HeLa cells were washed three times with prewarmed PBS, and the medium was replaced with fresh DMEM without antibiotics and fetal bovine serum. Monolayers of cells were infected with an exponentialphase bacterial culture $\left(10^{8} \mathrm{CFU}\right.$ per well), then incubated for $3 \mathrm{~h}$ at $37^{\circ} \mathrm{C}$ in a $5 \%$ $\mathrm{CO}_{2}$ atmosphere. After incubation, the wells were washed six times with PBS to remove unattached bacteria. HeLa cells were then disrupted with $0.1 \%$ SDS at $37^{\circ} \mathrm{C}$ for $5 \mathrm{~min}$. Lysate dilutions were plated on LB agar, and the attachment efficiency was determined by counting the colony-forming units (CFU) per milliliter. For each assay, at least three independent biological replicates were performed.

Quantitative RT-PCR. RNA samples were prepared using the TRIzol LS Reagent and were treated with RNase-Free DNase I to eliminate genomic DNA contamination. cDNA synthesis was conducted using the PrimeScript 1st Strand cDNA Synthesis Kit (Takara; \#D6110A). qRT-PCR analysis was conducted using SYBR Green PCR master mix (Applied Biosystems; \# 4367659) with the Applied Biosystems ABI 7300 sequence detection system. The 16S rRNA gene was used as a reference control to normalize differences in total RNA quantity among samples ${ }^{61}$. The relative difference in gene expression was calculated as the fold change using the formula $2^{-\Delta \Delta \text { ct }}$ (ref. 62). Expression change $>2$-fold and $P$ values $<0.05$ were considered to be statistically significant. At least three biological replicates were performed for each qRT-PCR analysis.

Western blot assays. Bacterial cultures were grown at $37^{\circ} \mathrm{C}$ in DMEM to an $\mathrm{OD}_{600}$ of $\approx 1.0$. The whole cells were harvested by centrifugation at $12,000 \mathrm{~g}$ for 5 min, washed with PBS ( $\mathrm{pH} 7.4$ ), centrifuged, resuspended in $\approx 100 \mu \mathrm{l}$ SDSpolyacrylamide gel electrophoresis solubilization buffer (normalized for $\mathrm{OD}_{600}$ ) and lysed at $100^{\circ} \mathrm{C}$ for $10 \mathrm{~min}$. Proteins were separated via $10 \%$ SDSpolyacrylamide gel electrophoresis and transferred to polyvinylidene difluoride membranes. The membranes were blocked with TBST (Tris-buffered saline with Tween 20) containing 5\% non-fat milk for $1 \mathrm{~h}$ at room temperature. Incubations with the primary antibody anti-His (1:2,500 dilution, CWBIO; \# CW0286) or
anti-FLAG (1:2,500 dilution, Sigma; \# F1804) and the secondary antibody goat anti-mouse-HRP (1:5,000 dilution, CWBIO; \# CW0102) were then carried out for $1 \mathrm{~h}$ at room temperature. Blots were washed in TBST followed by detection with the ECL enhanced chemiluminescence reagent.

Gel mobility shift assays. $6 \times$ His N-terminal-tagged BirA and $6 \times$ His $\mathrm{N}$-terminal-tagged Fur were purified using nickel columns (GE Healthcare; \#17057501). BirA gel shift assays and competition assays were performed using the DIG Gel Shift Kit, 2nd Generation (Roche; \#03353591910) according to the manufacturer's instructions. For each assay, biotin and ATP were added to the binding buffer ( $1 \mathrm{mM}$ Tris- $\mathrm{HCl}$ (pH 7.5); $0.1 \mathrm{mM}$ EDTA; $0.2 \mathrm{mM}$ dithiothreitol; $5 \mathrm{mM} \mathrm{MgCl}_{2} ; 10 \mathrm{mM} \mathrm{KCl}$ ) at final concentrations of $20 \mu \mathrm{M}$ and $1 \mathrm{mM}$, respectively ${ }^{50,63}$. Fur gel shift assays were performed using an EMSA Kit (Invitrogen; \#E33075) according to the manufacturer's instructions. For each assay, $\mathrm{Mn}^{2+}$ was added to the reaction buffer (offered by the kit) at a final concentration of $100 \mu \mathrm{M}$ (refs 64,65). Native polyacrylamide gels were used to separate free DNA probes and/or probe-protein complexes for each assay.

Quantitative PCR. To measure the enrichment of potential Fur-binding targets or BirA-binding targets in the immunoprecipitated DNA samples, relative-abundance qPCR was performed with SYBR green mix. Relative target levels were calculated using the $\Delta \Delta \mathrm{Ct}$ method $^{62}$. The results represent the average enrichment measured via $\mathrm{qPCR}$ in at least three biological replicate experiments.

Mouse colonization experiments. All animal experiments were performed according to the standards set forth in the Guide for the Care and Use of Laboratory Animals ${ }^{66}$. The experimental protocols were approved by the Institutional Animal Care Committee at Nankai University. Six-week-old female $\mathrm{BALB} / \mathrm{c}$ mice were maintained on either a normal diet (standard mice feed and sterilized water) or a biotin-rich diet (standard mice feed and sterilized water containing $10 \mathrm{mM}$ biotin) provided ad libitum for 7 days. In each group, ten mice were orally infected by pipette feeding of $100 \mu$ of PBS containing $10^{9} \mathrm{CFU}$ of bacteria (O157WT, O157- $\Delta$ birA, O157- $\Delta$ fur and O55WT) $\mathrm{Nal}^{\mathrm{R}}$ growing in logarithmic phase. The infected mice were anaesthetized in isoflurane and euthanized via cervical dislocation at $6 \mathrm{~h}$ after infection. The ileum and the colon were excised from the infected animals, and the luminal contents were then removed from each organ. Each portion of the intestine was washed vigorously with PBS three times and then weighed and homogenized in $0.5 \mathrm{ml}$ of PBS. The homogenates were subsequently diluted, and the samples were plated on LB agar containing nalidixic acid $\left(50 \mu \mathrm{g} \mathrm{ml}^{-1}\right)$ to determine the number of CFU per gram of organ tissue.

Quantification of biotin in mouse intestinal tracts. Six-week-old female BALB/c mice were fed a normal diet or biotin-rich diet ad libitum for 7 days. In each group seven mice were euthanized, and the luminal contents were obtained. The luminal contents were homogenized in $1 \mathrm{ml}$ of distilled water and centrifuged at $12,000 \mathrm{~g}$ at $4^{\circ} \mathrm{C}$ for $10 \mathrm{~min}$. The supernatant was diluted and used for biotin quantification. Biotin standards $\left(0-1,000 \mathrm{pmoll}^{-1}\right)$ were freshly prepared in HEPES buffer $(0.05 \mathrm{M}, \mathrm{pH} 7.0)$ from a stock solution of biotin $(100 \mathrm{nM})$. Biotin quantification was performed via a streptavidin-binding assay, as described previously ${ }^{67}$. Biotin concentrations were interpolated on the standard curve and the results expressed as picomoles of biotin per gram luminal contents.

\section{References}

1. Chen, H. D. \& Frankel, G. Enteropathogenic Escherichia coli: unravelling pathogenesis. FEMS Microbiol. Rev. 29, 83-98 (2005).

2. Welinder-Olsson, C. \& Kaijser, B. Enterohemorrhagic Escherichia coli (EHEC). Scand. J. Infect. Dis. 37, 405-416 (2005).

3. Vallance, B. A., Chan, C., Robertson, M. L. \& Finlay, B. B. Enteropathogenic and enterohemorrhagic Escherichia coli infections: emerging themes in pathogenesis and prevention. Can. J. Gastroenterol. 16, 771-778 (2002).

4. Karch, $\mathrm{H}$. The role of virulence factors in enterohemorrhagic Escherichia coli (EHEC)--associated hemolytic-uremic syndrome. Semin. Thromb. Hemost. 27, 207-213 (2001).

5. Garmendia, J., Frankel, G. \& Crepin, V. F. Enteropathogenic and enterohemorrhagic Escherichia coli infections: translocation, translocation, translocation. Infect. Immun. 73, 2573-2585 (2005).

6. Adu-Bobie, J. et al. Detection of intimins alpha, beta, gamma, and delta, four intimin derivatives expressed by attaching and effacing microbial pathogens. J. Clin. Microbiol. 36, 662-668 (1998).

7. Phillips, A. D. \& Frankel, G. Intimin-mediated tissue specificity in enteropathogenic Escherichia coli interaction with human intestinal organ cultures. J. Infect. Dis. 181, 1496-1500 (2000).

8. Fitzhenry, R. J. et al. Tissue tropism of enteropathogenic Escherichia coli strains belonging to the O55 serogroup. Infect. Immun. 70, 4362-4368 (2002). 
9. Chong, Y. et al. Human intestinal tissue tropism in Escherichia coli O157: H7--initial colonization of terminal ileum and Peyer's patches and minimal colonic adhesion ex vivo. Microbiology 153, 794-802 (2007).

10. Mundy, R. et al. Functional studies of intimin in vivo and ex vivo: implications for host specificity and tissue tropism. Microbiology 153, 959-967 (2007).

11. Fitzhenry, R. J. et al. Intimin type influences the site of human intestinal mucosal colonisation by enterohaemorrhagic Escherichia coli O157:H7. Gut 50, 180-185 (2002)

12. Reece, S. et al. Site-directed mutagenesis of intimin alpha modulates intiminmediated tissue tropism and host specificity. Mol. Microbiol. 40, 86-98 (2001).

13. Bardiau, M., Szalo, M. \& Mainil, J. G. Initial adherence of EPEC, EHEC and VTEC to host cells. Vet Res 41, 57 (2010).

14. Mellies, J. L., Barron, A. M. \& Carmona, A. M. Enteropathogenic and enterohemorrhagic Escherichia coli virulence gene regulation. Infect. Immun. 75, 4199-4210 (2007).

15. Barnett Foster, D. Modulation of the enterohemorrhagic E. coli virulence program through the human gastrointestinal tract. Virulence 4, 315-323 (2013).

16. House, B. et al. Acid-stress-induced changes in enterohaemorrhagic Escherichia coli O157: H7 virulence. Microbiology 155, 2907-2918 (2009).

17. de Jesus, M. C., Urban, A. A., Marasigan, M. E. \& Barnett Foster, D. E. Acid and bile-salt stress of enteropathogenic Escherichia coli enhances adhesion to epithelial cells and alters glycolipid receptor binding specificity. J. Infect. Dis. 192, 1430-1440 (2005).

18. Kenny, B., Abe, A., Stein, M. \& Finlay, B. B. Enteropathogenic Escherichia coli protein secretion is induced in response to conditions similar to those in the gastrointestinal tract. Infect. Immun. 65, 2606-2612 (1997).

19. Kus, J. V. et al. Bile salts induce resistance to polymyxin in enterohemorrhagic Escherichia coli O157:H7. J. Bacteriol. 193, 4509-4515 (2011).

20. Beckett, D. Biotin sensing at the molecular level. J. Nutr. 139, 167-170 (2009).

21. Said, H. M. Cell and molecular aspects of human intestinal biotin absorption. J. Nutr. 139, 158-162 (2009).

22. Beckett, D. Biotin sensing: universal influence of biotin status on transcription. Annu. Rev. Genet. 41, 443-464 (2007).

23. Otsuka, A. \& Abelson, J. The regulatory region of the biotin operon in Escherichia coli. Nature 276, 689-694 (1978).

24. Wilson, K. P., Shewchuk, L. M., Brennan, R. G., Otsuka, A. J. \& Matthews, B. W. Escherichia coli biotin holoenzyme synthetase/bio repressor crystal structure delineates the biotin- and DNA-binding domains. Proc. Natl Acad. Sci. USA 89, 9257-9261 (1992).

25. Feng, P. C. et al. Genetic diversity among clonal lineages within Escherichia coli O157:H7 stepwise evolutionary model. Emerg. Infect. Dis. 13, 1701-1706 (2007).

26. Zhou, Z. et al. Derivation of Escherichia coli O157:H7 from its O55:H7 precursor. PLoS ONE 5, e8700 (2010).

27. Beltrametti, F., Kresse, A. U. \& Guzman, C. A. Transcriptional regulation of the esp genes of enterohemorrhagic Escherichia coli. J. Bacteriol. 181, 3409-3418 (1999).

28. Dahan, S. et al. Transcriptome of enterohemorrhagic Escherichia coli O157 adhering to eukaryotic plasma membranes. Infect. Immun. 72, 5452-5459 (2004).

29. Carpenter, B. M., Whitmire, J. M. \& Merrell, D. S. This is not your mother's repressor: the complex role of fur in pathogenesis. Infect. Immun. 77, 2590-2601 (2009).

30. Keeney, K. M. \& Finlay, B. B. Enteric pathogen exploitation of the microbiotagenerated nutrient environment of the gut. Curr. Opin. Microbiol. 14, 92-98 (2011).

31. Bertin, Y. et al. Carbohydrate utilization by enterohaemorrhagic Escherichia coli O157:H7 in bovine intestinal content. Environ. Microbiol. 15, 610-622 (2013).

32. Reber, H. Microbial infections of the small and large intestine. Ther. Umsch. 37, 168-175 (1980).

33. Audia, J. P., Webb, C. C. \& Foster, J. W. Breaking through the acid barrier: an orchestrated response to proton stress by enteric bacteria. Int. J. Med. Microbiol. 291, 97-106 (2001)

34. Stojiljkovic, I., Baumler, A. J. \& Hantke, K. Fur regulon in gram-negative bacteria. Identification and characterization of new iron-regulated Escherichia coli genes by a fur titration assay. J. Mol. Biol. 236, 531-545 (1994).

35. Dong, T. \& Schellhorn, H. E. Global effect of RpoS on gene expression in pathogenic Escherichia coli O157:H7 strain EDL933. BMC Genomics. 10, 349 (2009).

36. Goldberg, M. D., Johnson, M., Hinton, J. C. \& Williams, P. H. Role of the nucleoid-associated protein Fis in the regulation of virulence properties of enteropathogenic Escherichia coli. Mol. Microbiol. 41, 549-559 (2001).

37. Riordan, J. T., Tietjen, J. A., Walsh, C. W., Gustafson, J. E. \& Whittam, T. S Inactivation of alternative sigma factor $54(\mathrm{RpoN})$ leads to increased acid resistance, and alters locus of enterocyte effacement (LEE) expression in Escherichia coli O157: H7. Microbiology 156, 719-730 (2010).
38. Trabulsi, L. R., Keller, R. \& Tardelli Gomes, T. A. Typical and atypical enteropathogenic Escherichia coli. Emerg. Infect. Dis. 8, 508-513 (2002).

39. Oliver, H. F. et al. Deep RNA sequencing of $L$. monocytogenes reveals overlapping and extensive stationary phase and sigma B-dependent transcriptomes, including multiple highly transcribed noncoding RNAs. BMC Genomics 10, 641 (2009).

40. Dotsch, A. et al. The Pseudomonas aeruginosa transcriptome in planktonic cultures and static biofilms using RNA sequencing. PLoS ONE 7, e31092 (2012).

41. Yoder-Himes, D. R. et al. Mapping the Burkholderia cenocepacia niche response via high-throughput sequencing. Proc. Natl Acad. Sci. USA 106, 3976-3981 (2009).

42. Mohawk, K. L. \& O’Brien, A. D. Mouse models of Escherichia coli O157:H7 infection and shiga toxin injection. J. Biomed. Biotechnol. 2011, 258185 (2011).

43. Lim, J. Y., Yoon, J. \& Hovde, C. J. A brief overview of Escherichia coli O157:H7 and its plasmid O157. J. Microbiol. Biotechnol. 20, 5-14 (2010).

44. Proulx, F., Turgeon, J. P., Delage, G., Lafleur, L. \& Chicoine, L. Randomized, controlled trial of antibiotic therapy for Escherichia coli O157:H7 enteritis. J. Pediatr. 121, 299-303 (1992).

45. Bosworth, B. T. et al. Vaccination with genetically modified Shiga-like toxin IIe prevents edema disease in swine. Infect. Immun. 64, 55-60 (1996).

46. Nataro, J. P. \& Kaper, J. B. Diarrheagenic Escherichia coli. Clin. Microbiol. Rev. 11, 142-201 (1998).

47. Yoon, J. W. \& Hovde, C. J. All blood, no stool: enterohemorrhagic Escherichia coli O157:H7 infection. J. Vet. Sci. 9, 219-231 (2008).

48. Datsenko, K. A. \& Wanner, B. L. One-step inactivation of chromosomal genes in Escherichia coli K-12 using PCR products. Proc. Natl. Acad. Sci. USA 97, 6640-6645 (2000).

49. Murphy, K. C. \& Campellone, K. G. Lambda Red-mediated recombinogenic engineering of enterohemorrhagic and enteropathogenic E. coli. BMC Mol. Biol. 4, 11 (2003).

50. Chakravartty, V. \& Cronan, J. E. Altered regulation of Escherichia coli biotin biosynthesis in BirA superrepressor mutant strains. J. Bacteriol 194, 1113-1126 (2012).

51. Rodionov, D. A., Mironov, A. A. \& Gelfand, M. S. Conservation of the biotin regulon and the BirA regulatory signal in Eubacteria and Archaea. Genome Res. 12, 1507-1516 (2002).

52. Jandu, N. et al. Enterohemorrhagic Escherichia coli O157:H7 gene expression profiling in response to growth in the presence of host epithelia. PLOS ONE 4, e4889 (2009)

53. Kim, Y., Oh, S., Park, S. \& Kim, S. H. Interactive transcriptome analysis of enterohemorrhagic Escherichia coli (EHEC) O157:H7 and intestinal epithelial HT-29 cells after bacterial attachment. Int. J. Food Microbiol. 131, 224-232 (2009).

54. Jandu, N. et al. Conditioned medium from enterohemorrhagic Escherichia coliinfected T84 cells inhibits signal transducer and activator of transcription 1 activation by gamma interferon. Infect. Immun. 74, 1809-1818 (2006).

55. Isabella, V. M. \& Clark, V. L. Deep sequencing-based analysis of the anaerobic stimulon in Neisseria gonorrhoeae. BMC Genomics 12, 51 (2011).

56. Robinson, M. D., McCarthy, D. J. \& Smyth, G. K. edgeR: a Bioconductor package for differential expression analysis of digital gene expression data. Bioinformatics 26, 139-140 (2010).

57. Davies, B. W., Bogard, R. W. \& Mekalanos, J. J. Mapping the regulon of Vibrio cholerae ferric uptake regulator expands its known network of gene regulation. Proc. Natl Acad. Sci. USA 108, 12467-12472 (2011).

58. Lucchini, S. et al. H-NS mediates the silencing of laterally acquired genes in bacteria. PLoS Pathog. 2, e81 (2006).

59. Jothi, R., Cuddapah, S., Barski, A., Cui, K. \& Zhao, K. Genome-wide identification of in vivo protein-DNA binding sites from ChIP-Seq data. Nucleic Acids Res. 36, 5221-5231 (2008).

60. Dibb-Fuller, M. P., Best, A., Stagg, D. A., Cooley, W. A. \& Woodward, M. J. An in-vitro model for studying the interaction of Escherichia coli $\mathrm{O} 157: \mathrm{H} 7$ and other enteropathogens with bovine primary cell cultures. J. Med. Microbiol. 50, 759-769 (2001)

61. Tasara, T. \& Stephan, R. Evaluation of housekeeping genes in Listeria monocytogenes as potential internal control references for normalizing mRNA expression levels in stress adaptation models using real-time PCR. FEMS Microbiol. Lett. 269, 265-272 (2007).

62. Livak, K. J. \& Schmittgen, T. D. Analysis of relative gene expression data using real-time quantitative PCR and the 2(-Delta Delta C(T)) Method. Methods 25, 402-408 (2001).

63. Barker, D. F. \& Campbell, A. M. Genetic and biochemical characterization of the birA gene and its product: evidence for a direct role of biotin holoenzyme synthetase in repression of the biotin operon in Escherichia coli. J. Mol. Biol. 146, 469-492 (1981).

64. Teixido, L., Carrasco, B., Alonso, J. C., Barbe, J. \& Campoy, S. Fur activates the expression of Salmonella enterica pathogenicity island 1 by directly interacting with the hilD operator in vivo and in vitro. PLoS ONE 6, e19711 (2011). 
65. Yuhara, S. et al. Pleiotropic roles of iron-responsive transcriptional regulator Fur in Burkholderia multivorans. Microbiology 154, 1763-1774 (2008).

66. Guide for the Care and Use of Laboratory Animals. National Institutes of Health, Publication No. 86-23 (1985).

67. Mishra, S., Storer, M. K., Sherwin, C. M. \& Lewis, J. G. A simple binding assay for the direct determination of biotin in urine. Clin. Chim. Acta 360, 60-66 (2005).

\section{Acknowledgements}

This work was supported by the National Key Program for Infectious Diseases of China (2013ZX10004216-001-001 and 2013ZX10004221), National 973 Program of China Grants (2013CB733904, 2012CB721101 and 2012CB721001), the International Science and Technology Cooperation Program of China (2012DFG31680 and 2013DFR30640) and the National Science Foundation of China (NSFC) Program (31030002, 31371259, 31270133 and 31470194)

\section{Author contributions}

L.W. and L.F. designed the research; B.Y. and F.W. performed the research; B.Y. and F.W. collected the data; L.W., L.F. and B.Y. analyzed the data; and L.W., L.F. and B.Y. wrote the paper.

\section{Additional information}

Accession codes: All sequence data have been deposited in the NCBI SRA database under the accession codes SRR1619463, SRR1619464, SRR1619465 and SRR1641752 for the RNA-seq data and SRR1621223 and SRR1621224 for the ChIP-seq data.

Supplementary Information accompanies this paper at http://www.nature.com/ naturecommunications

Competing financial interests: There are no competing financial interests.

Reprints and permission information is available online at http://npg.nature.com/ reprintsandpermissions/

How to cite this article: Yang, B. et al. Enterohemorrhagic Escherichia coli senses low biotin status in the large intestine for colonization and infection. Nat. Commun. 6:6592 doi: 10.1038/ncomms7592 (2015).

(c) (i) This work is licensed under a Creative Commons Attribution 4.0 International License. The images or other third party material in this article are included in the article's Creative Commons license, unless indicated otherwise in the credit line; if the material is not included under the Creative Commons license, users will need to obtain permission from the license holder to reproduce the material. To view a copy of this license, visit http://creativecommons.org/licenses/by/4.0/ 